\title{
Fabrication and Enhanced Vickers Hardness of Electrodeposited Co-Cu Alloy Film with High Composition Gradient
}

\author{
Hiroyuki Hagiwara*1, Yoshihisa Kaneko*2 and Makoto Uchida \\ Department of Mechanical Engineering, Osaka City University, Osaka 558-8585, Japan
}

By applying an oscillating potential wave, we obtained an electrodeposited $\mathrm{Co}-\mathrm{Cu}$ alloy film in which the Co concentration changed periodically at a short modulation wave length. A triangular Co concentration modulation was observed along the film growth direction. The local composition gradient became as high as $50 \mathrm{at} \% / \mu \mathrm{m}$. The Vickers hardness of the composition gradient film was $380 \mathrm{HV}$. Because this value was much higher than that of simple electrodeposited $\mathrm{Co}-\mathrm{Cu}$ alloy films, contribution of the composition-gradient structure to hardness was suggested. [doi:10.2320/matertrans.MT-M2019334]

(Received November 13, 2019; Accepted January 14, 2020; Published February 17, 2020)

Keywords: composition gradient, hardness, electrodeposition, Co-Cu alloy

\section{Introduction}

The strength of an electrodeposited metallic film can be improved by modification of a microstructure. For example, high strength has been reported in nanograined nickel ${ }^{1,2)}$ and copper ${ }^{3-5}$ ) films that were produced by pulsed-electrodeposition techniques. High strength was also achieved in multilayered films consisting of alternate stacks of two dissimilar layers fabricated by electrodeposition ${ }^{6-10)}$ and physical deposition techniques. ${ }^{11-15)}$ To understand the strength increase in a multilayered film, several micromechanisms including dislocation pile-ups at interfaces, a hairpin-shaped dislocation gliding within a component layer, and etc. have been proposed. ${ }^{16)}$ These models assume the existence of a well-defined interface between adjoining layers.

Meanwhile, a diffused interface could likely contribute to a strengthened multilayer film. Oberle et al. ${ }^{9)}$ reported that the annealing at $400^{\circ} \mathrm{C}$ for $30 \mathrm{~min}$ led to an increase in hardness on an electrodeposited $\mathrm{Ni} / \mathrm{Cu}$ multilayered film, while the hardness values of well-annealed films decreased. The decreased hardness of the well-annealed samples can be understood simply from the unstable structure against heat treatment, because the $\mathrm{Ni}$ and $\mathrm{Cu}$ layers are easily intermixed at an elevated temperature. However, the increased strength in the shortly annealed sample could not be explained by the strengthening models based on the defined interfaces. In their literature, some interdiffusion between the layers was suggested at the shortly annealed sample. The interdiffused interface should produce a region of gradient composition. Accordingly, the authors conceive the idea that a composition-gradient area in a multilayered film can contribute to strengthening.

A single-bath electrodeposition technique using a rectangle potential wave allows us to produce a multilayered metallic film, owing to the difference in standard electrode potentials between metals contained in electrolyte. However, only limited couples including $\mathrm{Ni} / \mathrm{Cu},{ }^{6-10)} \mathrm{Co} / \mathrm{Cu},{ }^{17-19)} \mathrm{Ag} / \mathrm{Pd},{ }^{20}$ $\mathrm{Zn} / \mathrm{Co}^{21)}$ and etc. have been able to be fabricated. The $\mathrm{Co} /$ $\mathrm{Cu}$ couple is a representative multilayer that can be obtained

\footnotetext{
${ }^{* 1}$ Graduate Student, Osaka City University

${ }^{* 2}$ Corresponding author, E-mail: kaneko@eng.osaka-cu.ac.jp
}

by the single-bath technique, as well as the $\mathrm{Ni} / \mathrm{Cu}$ multilayer. The $\mathrm{Co}-\mathrm{Cu}$ alloy separates into $\mathrm{Co}-$ and $\mathrm{Cu}$-rich solid solutions under equilibrium, while the $\mathrm{Ni}-\mathrm{Cu}$ and the $\mathrm{Ag}-\mathrm{Pd}$ alloys are all-proportional solid solutions. ${ }^{22)}$ Hence, in the $\mathrm{Co} / \mathrm{Cu}$ multilayers, an interdiffused region is hardly formed by annealing, unlike in the multilayers consisting of two elements of the all-proportional solid solution type. Hence, in the present study, we attempted to fabricate a $\mathrm{Co}-\mathrm{Cu}$ alloy film with high composition gradient only by a special electrodeposition technique in which an applied potential changes continuously. The hardness of the compositiongradient $\mathrm{Co}-\mathrm{Cu}$ alloy film was measured. The authors compared the hardness value with those of $\mathrm{Co}-\mathrm{Cu}$ alloy films grown under constant potentials and a $\mathrm{Co} / \mathrm{Cu}$ multilayered film.

\section{Experimental Procedure}

In an electrolytic solution containing two types of metallic ions, the deposit composition depends on the applied potential. In the solution for $\mathrm{Co}-\mathrm{Cu}$ alloy electrodeposition, the standard electrode potential of cobalt $(-0.283 \mathrm{~V})$ is lower than that of copper $(+0.340 \mathrm{~V}) .{ }^{23)}$ In this case, both cobalt and copper deposit simultaneously at a high cathodic potential, while almost pure copper deposits exclusively at a low potential. When the $\mathrm{Cu}$ ion content in a solution was considerably lowered in comparison with the Co ion content, a Co-rich alloy was deposited at a high potential (or a high current). ${ }^{17)}$ Hence, we used the solution where the content of copper sulfate was lower than that of cobalt sulfate by a factor of approximately one hundred. The contents of the solution used in the present study are listed in Table 1.

During electrodeposition, the solution was maintained at $313 \mathrm{~K}$ and was agitated. A potentiostat (Hokuto-Denko HA151A) was used to apply a potential. The potential was measured with an $\mathrm{Ag}-\mathrm{AgCl}$ reference electrode.

A Pt substrate was used for the electrodeposition of the films that were analyzed by X-ray diffraction (XRD) and by energy dispersive spectroscopy (EDS) in a scanning electron microscope (SEM). The electrodeposited films for EDS analysis in a transmission electron microscope (TEM) and for the hardness measurement were deposited on copper 
Table 1 Solution composition for the electrodeposition.

\begin{tabular}{cc}
\hline Component & Concentration \\
\hline $\mathrm{CoSo}_{4} \cdot 7 \mathrm{H}_{2} \mathrm{O}$ & $300 \mathrm{~g} / \mathrm{L}$ \\
$\mathrm{CuSO}_{4} \cdot 5 \mathrm{H}_{2} \mathrm{O}$ & $1.9 \mathrm{~g} / \mathrm{L}$ \\
$\mathrm{Ho} \mathrm{O}_{3}$ & $30 \mathrm{~g} / \mathrm{L}$ \\
$\mathrm{S} \mathrm{a} \mathrm{c} \mathrm{charin}_{3}$ & $3.05 \mathrm{~m} / \mathrm{L}$ \\
\hline
\end{tabular}

substrates that were annealed at $973 \mathrm{~K}$ for $1 \mathrm{~h}$ in vacuum. All the substrates were covered with lacquer for insulation, except on a circular area $(\phi 9 \mathrm{~mm})$ that was exposed in the solution.

In the present electrodeposition, we used three types of potential waveforms, as shown in Fig. 1. At a constant potential corresponding to a conventional electrodeposition (Fig. 1(a)), an electrodeposited film should be a $\mathrm{Co}-\mathrm{Cu}$ alloy with a homogeneous composition distribution with respect to the growth direction. An electrodeposited $\mathrm{Co}-\mathrm{Cu}$ alloy film fabricated under a constant potential is denoted as a "simple" $\mathrm{Co}-\mathrm{Cu}$ alloy film in this study. When applying two different potentials alternately (Fig. 1(b)), we can obtain a $\mathrm{Co} / \mathrm{Cu}$ multilayered film. Figure 1(c) shows an oscillating potential wave at which the potential changes continuously. Because the deposit composition is sensitive to the potential, a fabricated $\mathrm{Co}-\mathrm{Cu}$ alloy film can have composition modulation.

We first electrodeposited simple $\mathrm{Co}-\mathrm{Cu}$ alloy films to investigate the dependence of deposit composition on the applied potential. The electrodeposition tests were conducted at twelve constant potentials ranging from -720 to $-590 \mathrm{mV}$ vs standard hydrogen electrode (SHE). The thickness of the deposits was $3 \mu \mathrm{m}$. The Co compositions of the obtained deposits were analyzed with the EDS system equipped with the JEOL JSM 6500F SEM.

The composition-gradient $\mathrm{Co}-\mathrm{Cu}$ alloy film was electrodeposited using the same solution. At the beginning of electrodeposition, the applied potential was $-655 \mathrm{mV}$ vs SHE. For monitoring film growth, we estimated an instantaneous deposit thickness from a current consumed during $0.01 \mathrm{~s}$. The film growth during this duration was estimated by the Faraday's law. The current efficiency was assumed to be $75 \%$ for the thickness calculation. At every $0.01 \mathrm{~s}$, the potential was adjusted such that the chemical composition changes linearly with respect to thickness, using the potential-Co composition relation that was obtained at the abovementioned experiment. The potential increment (or decrement) direction was inverted when the estimated composition-gradient thickness became $0.5 \mu \mathrm{m}$. During the electrodeposition, the applied potential was oscillated approximately within the range from -655 to $-625 \mathrm{mV}$ vs SHE. The total thickness of the composition-gradient film was $3 \mu \mathrm{m}$.

The microstructure of the composition-gradient $\mathrm{Co}-\mathrm{Cu}$ alloy film was characterized by XRD using $\mathrm{Co}-\mathrm{K} \alpha$ radiation (Rigaku RINT-2200) and by the EDS analysis with TEM (JEOL JEM-2100). To prepare the thin foil, the electrodeposited surface was additionally covered by a thick electrodeposited copper. Subsequently, the sample was machined to a thin disc of $3 \mathrm{~mm}$ diameter; the disc surface was perpendicular to the composition-gradient film. The disc was thinned with a dimple grinder and an Ar-ion milling device.

The Vickers hardness of the electrodeposited films was measured with the Shimadzu DUH-W201. The hardness tests were conducted on the samples in which the electrodeposited films were not removed from the copper substrates. The indentation force and the measurement number for each sample were $10 \mathrm{mN}$ and 10 , respectively. The hardness measurements were conducted also on the electrodeposited films including the electrodeposited copper, cobalt, $\mathrm{Co}-\mathrm{Cu}$ alloy, and $\mathrm{Co} / \mathrm{Cu}$ multilayer. These films had a $3-\mu \mathrm{m}$ thickness. The individual layer thickness of the $\mathrm{Co} / \mathrm{Cu}$ multilayer was $0.5 \mu \mathrm{m}$.

\section{Results and Discussion}

Figure 2 shows the Co concentrations of the simple $\mathrm{Co}-\mathrm{Cu}$ films grown under the constant applied potentials ranging from -720 to $-590 \mathrm{mV}$ vs SHE. The Co concentration of the simple $\mathrm{Co}-\mathrm{Cu}$ alloy films decreased with increasing potential. It is thus suggested that the cobalt concentration of an electrodeposited film is adjustable with the applied potential, at the least in this potential range.

A cross section of the $\mathrm{Co}-\mathrm{Cu}$ alloy film fabricated by the oscillating potential was analyzed by the EDS in the TEM. Figures 3(a) and 3(b) show the distributions of cobalt and copper, respectively. The intensities of these two elements fluctuated with respect to the growth direction. Point analyses along a line parallel to the growth direction were also conducted on the composition gradient film to quantify Co concentrations. Figure 3(c) shows the Co concentrations, plotted against the position $x$. The position $x=0$ coincides (a) constant

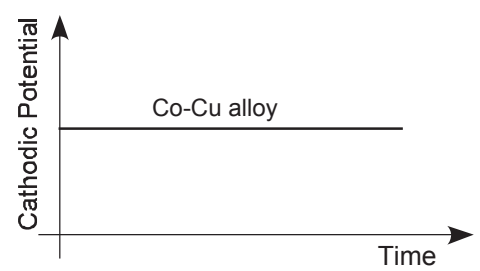

(b) rectangle

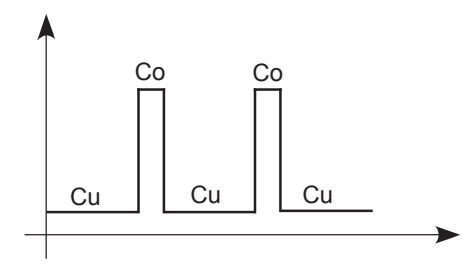

(c) oscillating

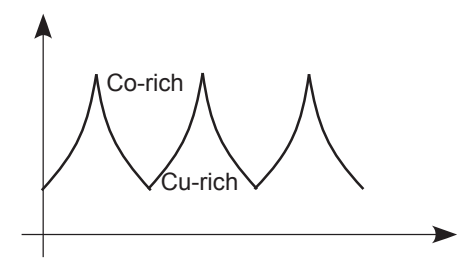

Fig. 1 Schematic illustrations of potential waveforms for electrodeposition: (a) constant, (b) rectangle, (c) oscillating potential waves for fabricating simple, multilayered, and composition gradient $\mathrm{Co}-\mathrm{Cu}$ films, respectively. 


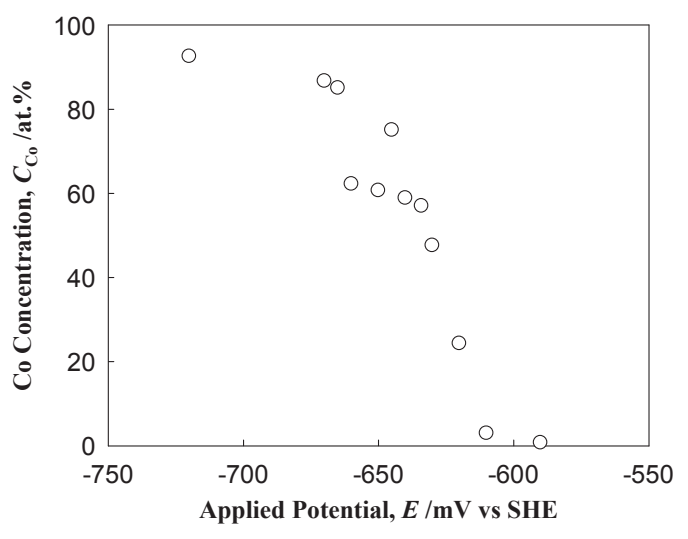

Fig. 2 Relationship between the Co concentrations of electrodeposited $\mathrm{Co}-\mathrm{Cu}$ films and the applied potentials that were constant during electrodeposition.
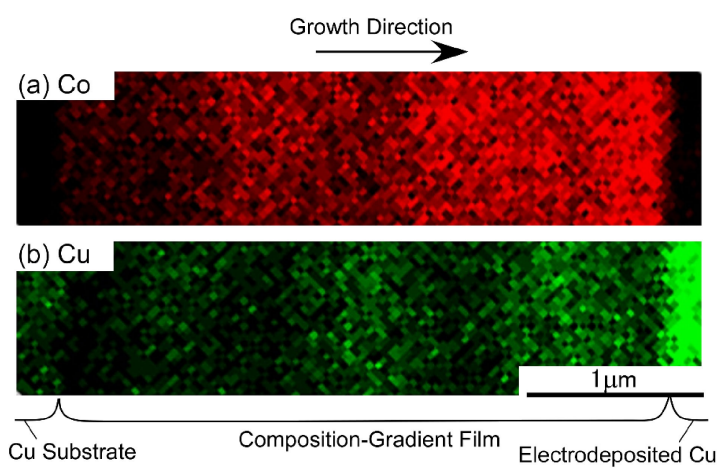

(c) Co concentration

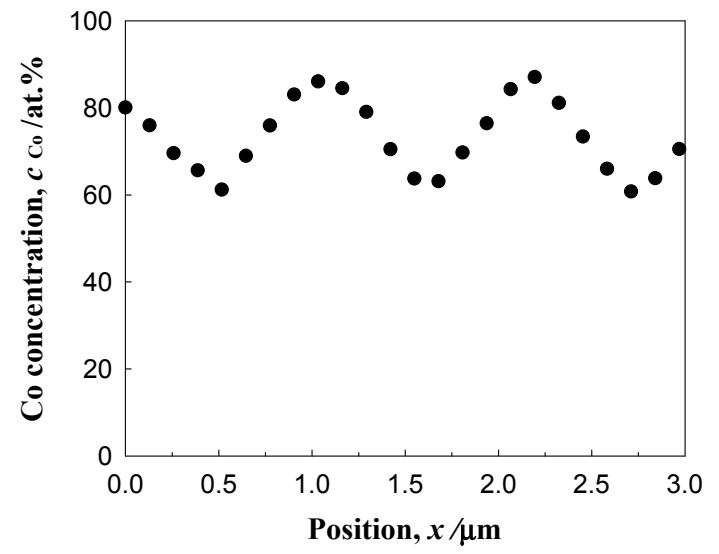

Fig. 3 EDX maps of (a) $\mathrm{Co}$ and (b) $\mathrm{Cu}$ at cross section of the $\mathrm{Co}-\mathrm{Cu}$ alloy film fabricated by the oscillating potential. A change in Co concentration along the growth direction is shown in (c).

with the original surface of the copper substrate surface. The Co concentration changed periodically and exhibited a triangular form, where the maximum and minimum $\mathrm{Co}$ concentrations were approximately 87 at $\%$ and 61 at $\%$, respectively. A half wavelength of the periodic change was approximately $0.5 \mu \mathrm{m}$. Because of the triangular form, this $\mathrm{Co}-\mathrm{Cu}$ alloy film can be regarded as alternate stacks of two layers having positive and negative composition gradients. The absolute values of the gradients were approximately 50 at $\% / \mu \mathrm{m}$ for both the positive and negative gradients. It is noteworthy that such a high composition gradient cannot be attained in a conventional composition-gradient material at which the concentration changes monotonically throughout

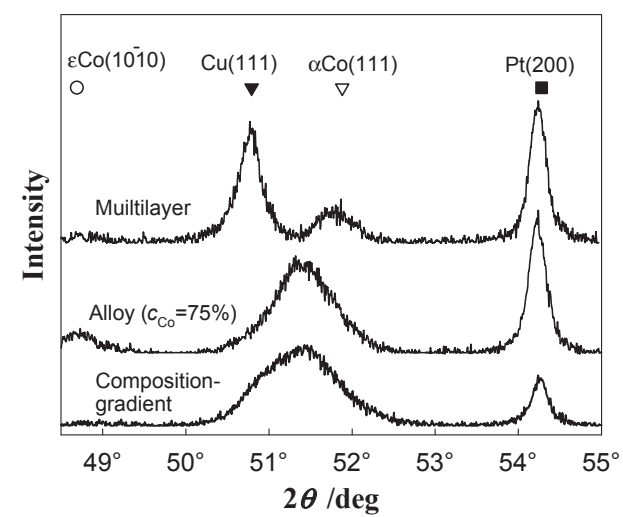

Fig. 4 XRD patterns of the electrodeposited $\mathrm{Co} / \mathrm{Cu}$ multilayer, simple $\mathrm{Co}-$ $\mathrm{Cu}$ alloy $\left(c_{\mathrm{Co}}=75 \mathrm{at} \%\right)$, and composition-gradient $\mathrm{Co}-\mathrm{Cu}$ alloy films.

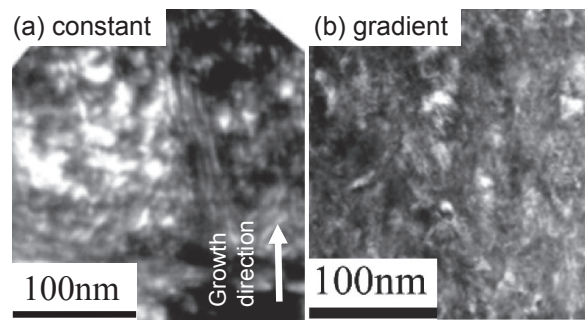

Fig. 5 Typical dark-field TEM images of (a) the Co-rich layer of the $\mathrm{Co} /$ $\mathrm{Cu}$ multilayered film with $500 \mathrm{~nm}$ layer thickness and (b) the $\mathrm{Co}-\mathrm{Cu}$ composition-gradient film.

the thickness. The present periodic microstructure enabled us to achieve such a high composition gradient in the entire film.

Figure 4 shows the XRD patterns of the compositiongradient $\mathrm{Co}-\mathrm{Cu}$ alloy, the simple $\mathrm{Co}-\mathrm{Cu}$ alloy of $c_{\mathrm{Co}}=$ 75 at $\%$, and the $\mathrm{Co} / \mathrm{Cu}$ multilayered film. In the XRD pattern of the multilayered film, two fcc (111) peaks corresponding to the $\mathrm{Co}$ and $\mathrm{Cu}$ layers are visible. The composition-gradient and the simple $\mathrm{Co}-\mathrm{Cu}$ alloy films showed single (111) peaks. The fcc (111) peak angle of the composition-gradient film was $2 \theta=51.5^{\circ}$ and was nearly equal to that of the simple $\mathrm{Co}-\mathrm{Cu}$ alloy film of $c_{\mathrm{Co}}=75 \mathrm{at} \%$. This peak angle is consistent with the EDS analysis that the average Co concentration of the composition gradient film was 74 at $\%$. It is anticipated that the lattice parameter of the compositiongradient film spread over a certain range because the Co composition changed from 61 to 87 at\%. However, the composition-gradient film revealed the single peak, which was similar to that of the simple $\mathrm{Co}-\mathrm{Cu}$ alloy. Hence, one can consider that the lattice parameters were deviated from intrinsic values near the regions with the lower and upper Co concentration peaks.

Typical TEM images of the electrodeposited films are presented in Fig. 5. Figure 5(a) is the microstructure of a Co-rich layer of the $\mathrm{Co} / \mathrm{Cu}$ multilayers, where the applied potential was constant during the growth of each layer. Elongated grains and equiaxed grains whose sizes (or thicknesses) were typically $10-30 \mathrm{~nm}$ are visible. Figure 5(b) is the microstructure of the composition-gradient $\mathrm{Co}-\mathrm{Cu}$ alloy, where the applied potential changed during the film growth. We can recognize fine grains whose size are 10$20 \mathrm{~nm}$. 


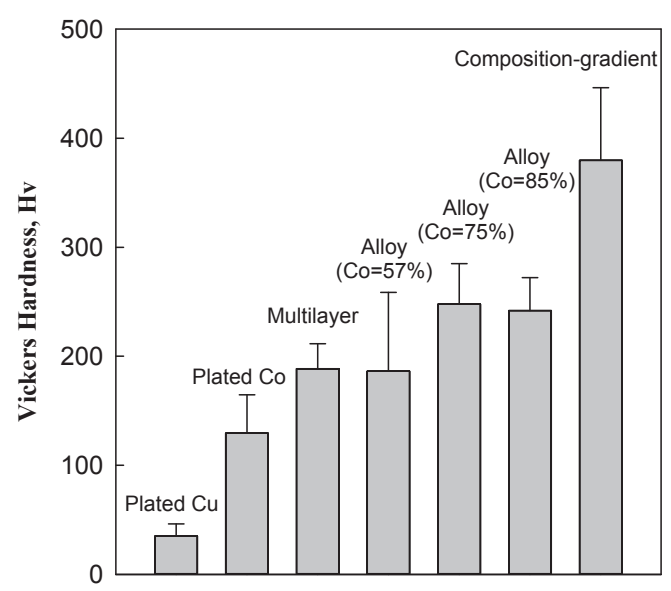

Fig. 6 Vickers hardness values of the electrodeposited copper, cobalt, $\mathrm{Co} /$ $\mathrm{Cu}$ multilayer, simple $\mathrm{Co}-\mathrm{Cu}$ alloys, and composition-gradient $\mathrm{Co}-\mathrm{Cu}$ alloy films.

The Vickers hardness tests were conducted on the composition-gradient, simple $\mathrm{Co}-\mathrm{Cu}$ alloy, $\mathrm{Co} / \mathrm{Cu}$ multilayer, electrodeposited cobalt and copper films. Three kinds of the simple $\mathrm{Co}-\mathrm{Cu}$ alloy films electrodeposited at $E=$ $-634,-645$, and $-665 \mathrm{mV}$ vs SHE were prepared for the hardness measurement. These Co concentrations were almost included within the oscillating Co concentrations in the composition-gradient film. Figure 6 shows the Vickers hardness values of these films. It is noted that the measured hardness values should be affected by the soft copper substrate. Hence, in this study, we used a hardness value to estimate the relative strength among the samples. The Vickers hardness values increased in the ascending order of the electrodeposited copper, cobalt, $\mathrm{Co} / \mathrm{Cu}$ multilayer, simple $\mathrm{Co}-\mathrm{Cu}$ alloys with the high Co contents, and compositiongradient films. The Vickers hardness of the compositiongradient film was amounted to $380 \mathrm{HV}$, and this value was certainly higher than those of the $\mathrm{Co} / \mathrm{Cu}$ multilayered film and the simple $\mathrm{Co}-\mathrm{Cu}$ alloy films whose hardness values were approximately from $190 \mathrm{HV}$ to $250 \mathrm{HV}$. Because the Co concentrations of the simple $\mathrm{Co}-\mathrm{Cu}$ alloy films $\left(c_{\mathrm{Co}}=57\right.$, 75 , and 85 at $\%$ ) were almost included in the Co concentration range of the composition-gradient film, the enhanced hardness in the composition-gradient film would not result from solid-solution hardening. Furthermore, no significant difference between grain sizes of the composition-gradient film and the Co-rich phase grown at a constant potential. Accordingly, it was suggested that strength of $\mathrm{Co}-\mathrm{Cu}$ alloy was possibly enhanced by introducing the high compositiongradient structure. However, the hardening mechanisms have not clarified yet. The microstructure producing the single XRD peak (Fig. 4) may be related to the hardening in the composition-gradient film.

\section{Conclusions}

(1) By applying oscillating potential that changed continuously, we could electrodeposit a $\mathrm{Co}-\mathrm{Cu}$ alloy film having a periodic triangular Co concentration change. The TEM/EDS analysis on the film showed that the minimum and maximum peaks of the Co concentration were 61 at $\%$ and 87 at\%, respectively. The half wavelength of the periodic change was $0.5 \mu \mathrm{m}$. This change in the Co concentration gave the local composition gradient of approximately $50 \mathrm{at} \% / \mu \mathrm{m}$.

(2) The Vickers hardness of the composition-gradient Co$\mathrm{Cu}$ alloy film was $380 \mathrm{HV}$. This value was higher than those of the simple $\mathrm{Co}-\mathrm{Cu}$ alloy films, where the $\mathrm{Co}$ concentrations were almost included within the Co concentration range of the composition-gradient alloy film.

\section{Acknowledgments}

This study was supported by JSPS KAKENHI for Scientific Research in Innovative Areas "MFS Materials Science" (Grant Number 18H05483), and JSPS KAKENHI for Scientific Research (C) (Grant Number 19K05034).

\section{REFERENCES}

1) H. Natter, M. Schmelzer and R. Hempelmann: J. Mater. Res. 13 (1998) 1186-1197.

2) A.M. El-Sherik and U. Erb: J. Mater. Sci. 30 (1995) 5743-5749.

3) H. Natter and R. Hempelmann: J. Phys. Chem. 100 (1996) 1952519532.

4) E. Ma, Y.M. Wang, Q.H. Lu, M.L. Sui, L. Lu and K. Lu: Appl. Phys. Lett. 85 (2004) 4932-4934.

5) Y.F. Shen, L. Lu, Q.H. Lu, Z.H. Jin and K. Lu: Scr. Mater. 52 (2005) 989-994.

6) S. Menezes and D.P. Anderson: J. Electrochem. Soc. 137 (1990) 440 444.

7) D.M. Tench and J.T. White: J. Electrochem. Soc. 138 (1991) 37573758.

8) D. Simunovich, M. Schlesinger and D.D. Snyder: J. Electrochem. Soc. 141 (1994) L10-L11.

9) R.R. Oberle and R.C. Cammarata: Scr. Metall. Mater. 32 (1995) 583588.

10) Y. Kaneko, Y. Mizuta, Y. Nishijima and S. Hashimoto: J. Mater. Sci. 40 (2005) 3231-3236.

11) A. Misra, M. Verdier, Y.C. Lu, H. Kung, T.E. Mitchell, M. Nastasi and J.D. Embury: Scr. Mater. 39 (1998) 555-560.

12) H. Geisler, K.O. Schweitz, J. Chevallier, J. Bottiger and K. Samwer: Philos. Mag. A 79 (1999) 485-500.

13) J. McKeown, A. Misra, H. Kung, R.G. Hoagland and M. Nastasi: Scr. Mater. 46 (2002) 593-598.

14) J.Y. Zhang, X. Zhang, R.H. Wang, S.Y. Lei, P. Zhang, J.J. Niu, G. Liu, G.J. Zhang and J. Sun: Acta Mater. 59 (2011) 7368-7379.

15) B. Ham and X. Zhang: Mater. Sci. Eng. A 528 (2011) 2028-2033.

16) A. Misra, J.P. Hirth and H. Kung: Philos. Mag. A 82 (2002) 29352951.

17) L. Péter, A. Cziráki, Z. Pogániy, Z. Kupay, M. Uhlemann, M. Herrich, B. Arnold, T. Bauer and K. Wetzig: J. Electrochem. Soc. 148 (2001) C168-C176.

18) J.J. Kelly, M. Cantoni and D. Landolt: J. Electrochem. Soc. 148 (2001) C620-C626.

19) M. Uhlemann, A. Gebert, M. Herrich, A. Krause, A. Cziraki and L. Schultz: Electrochim. Acta 48 (2003) 3005-3011.

20) U. Cohen, F.B. Koch and R. Sard: J. Electrochem. Soc. 130 (1983) 1987-1995.

21) M.E. Bahrololoom, D.R. Gabe and G.D. Wilox: Trans. Inst. Met. Finish. 82 (2004) 51-58.

22) W.F. Gale and T.C. Totemeier: Smithells Metals Reference Book Eighth Edition, Chapter 11, (Elsevier, Oxford, 2004) pp. 1-523.

23) W. Plieth: Electrochemistry for Materials Science, (Elsevier, Oxford, 2008) pp. 71-80. 